Article

\title{
Microalgae-Based Fluorimetric Bioassays for Studying Interferences on Photosynthesis Induced by Environmentally Relevant Concentrations of the Herbicide Diuron
}

\author{
Gerardo Grasso $^{1, *(\mathbb{D})}$, Giulia Cocco ${ }^{2}$, Daniela Zane ${ }^{1}$, Chiara Frazzoli ${ }^{3}\left[\right.$ and Roberto Dragone $^{1}$ \\ 1 Istituto per lo Studio dei Materiali Nanostrutturati Sede Sapienza, Consiglio Nazionale delle Ricerche, P. le \\ Aldo Moro 5, 00185 Rome, Italy; daniela.zane@cnr.it (D.Z.); roberto.dragone@cnr.it (R.D.) \\ 2 Dipartimento di Scienze e Tecnologie per l'Agricoltura, le Foreste, la Natura e l'Energia, Università degli Studi \\ della Tuscia, 01100 Viterbo, Italy; dr.giulia.cocco@gmail.com \\ 3 Dipartimento Malattie Cardiovascolari e Endocrino-metaboliche, e Invecchiamento, Istituto Superiore di \\ Sanità, Via Giano della Bella, 34, 00162 Rome, Italy; chiara.frazzoli@iss.it \\ * Correspondence: gerardo.grasso@cnr.it
}

check for

updates

Citation: Grasso, G.; Cocco, G.; Zane,

D.; Frazzoli, C.; Dragone, R.

Microalgae-Based Fluorimetric

Bioassays for Studying Interferences

on Photosynthesis Induced by

Environmentally Relevant

Concentrations of the Herbicide

Diuron. Biosensors 2022, 12, 67.

https://doi.org/10.3390/

bios12020067

Received: 27 December 2021

Accepted: 19 January 2022

Published: 25 January 2022

Publisher's Note: MDPI stays neutral with regard to jurisdictional claims in published maps and institutional affiliations.

Copyright: (C) 2022 by the authors. Licensee MDPI, Basel, Switzerland. This article is an open access article distributed under the terms and conditions of the Creative Commons Attribution (CC BY) license (https:// creativecommons.org/licenses/by/ $4.0 /)$.
Abstract: The widespread agricultural use of the phenylurea herbicide Diuron (DCMU) requires the investigation of ecotoxicological risk in freshwater and soil ecosystems in light of potential effects on non-target primary producers and a heavier effect on higher trophic levels. We used microalgae-based fluorimetric bioassays for studying the interferences on the photosynthesis of a freshwater and soil model green microalga (Chlamydomonas reinhardtii) induced by environmentally relevant concentrations of the herbicide DCMU. Measurements of steady-state chlorophyll $a$ (Chl-a) fluorescence emission spectra were performed; as well, the kinetics of the Chl-a fluorescence transient were recorded. Percentage indexes of interference on photosynthesis were calculated after comparison of steady-state and kinetic Chl-a fluorescence measurements of DCMU-exposed and control C. reinhardtii cell suspensions. The results obtained after $30 \mathrm{~min}$ exposure to the herbicide DCMU confirmed a significant inhibitory effect of DCMU $2 \mu \mathrm{g} / \mathrm{L}$, and no significant differences between

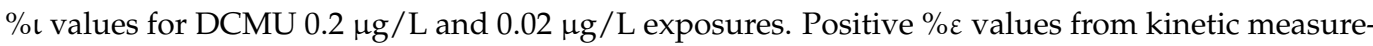
ments of the Chl-a fluorescence transient confirmed the same interfering effect of $2 \mu \mathrm{g} / \mathrm{L}$ DCMU on PSII photochemistry in the exposed C. reinhardtii cell suspensions. Negative values of $\% \varepsilon$ observed for 0.2 and $0.02 \mu \mathrm{g} / \mathrm{L}$ DCMU exposures could be attributable to a presumptive 'stimulatory-like' effect in the photochemistry of photosynthesis. Short-term exposure to sub- $\mu \mathrm{g} / \mathrm{L}$ DCMU concentration $(\leq 0.2 \mu \mathrm{g} / \mathrm{L})$ affects the photosynthetic process of the model microalga C. reinhardtii. Similar environmental exposures could affect natural communities of unicellular autotrophs, with hardly predictable cascading secondary effects on higher trophic levels.

Keywords: ecosystem health; ecotoxicology; herbicides; microalgae; chlorophyll fluorescence; Kautsky effect

\section{Introduction}

In recent years, the increasing use of phenylurea herbicides (PUHs) as well as residual activity PUHs and their degradation products in crops, soils, and freshwaters pose a serious risk to the environment and human health. Diuron (3-(3,4-dichlorophenyl)-1, 1dimethylurea or DCMU) is one of the most relevant members of substituted phenylurea herbicides and a chemical of great agronomical importance worldwide [1]. DCMU is extensively used as a selective pre-emergence herbicide against mono- and dicotyledonous weeds in agricultural crop areas of citrus, grapes, cotton, sugar cane, alfalfa, and wheat. Furthermore, DCMU is used for general weed control in non-crop areas (e.g., roads, garden paths, railway lines, industrial sites, rights-of-way, around farm buildings, on irrigation, and drainage ditches) $[2,3]$. It can also be used as mildewcide, as an algaecide in commercial 
fish productions, and as antifouling in paint biocide production [4]. DCMU also showed its efficacy against mosses and as a soil-sterilizing agent [5].

Data on adsorption of PUHs by temperate soils are largely available, while very few data are available for tropical soils [6]. Studies about environmental fate and behavior highlighted that DCMU is relatively persistent in the environment; it is mobile in soil and relatively stable in water [3,7]. DCMU is prone to phenomena such as agricultural run-off, leaching (during rain events), and migration to both surface and groundwater aquatic environments. Available toxicity data suggest that DCMU can cause adverse effects on non-target organisms such as fish [8-11]. A knowledge gap still exists in the literature about DCMU toxicity on other non-target organisms such as amphibians [8].

Unicellular green algae are primary producers at the basis of the aquatic food chain, thus bearing a high ecological relevance. The ecological relevance of unicellular green algae implies that adverse effects on these microorganisms can negatively influence higher trophic levels, including zooplankton and fish [12]. As a consequence of increased DCMU (as for other photosystem II inhibitor herbicides) residues in the environment, acute adverse effects can occur on natural populations of unicellular autotrophs. To date, little is known about potential adverse ecological effects on a longer timescale. These effects can include chronic adverse effects on natural communities, cascading secondary effects on other communities' ecological processes, and hardly predictable effects on different trophic levels and, ultimately, on ecosystems.

Recently, a model assessing the effect of high-frequency pulses (simulating exposure in agricultural applications and run-off) of DCMU exposure of freshwater benthic biofilms suggested that adverse impacts are very likely [13]. The influence of water flow conditions on DCMU bioaccumulation by freshwater biofilms has also been recently assessed [14]. The green microalga Chlamydomonas reinhardtii contributes to the primary production of a wide range of natural habitats, including freshwater (e.g., small pools, ditches, pelagic zone of lakes) and soils (e.g., temperate cultivated fields) [15]. In addition, C. reinhardtii has been widely used as a model organism for understanding the response to herbicides, the mechanisms behind herbicide action, as well as being a biologiacal indicator of pesticide toxicity in the environment [16]. Bioassays based on ecologically important and model organisms are crucial to study and screen chemical hazards in real-life matrices, as well as for diagnostic assessment of acute ecotoxicity.

In the present study, the freshwater and soil model microalga Chlamydomonas reinhardtii was used in microalgae-based fluorimetric bioassays to study acute interferences on photosynthesis following short-term $(30 \mathrm{~min}$ ) exposures to environmentally relevant concentrations of the herbicide DCMU (concentration range 0.02-2 $\mu \mathrm{g} / \mathrm{L}$ ). The concentration of $2 \mu \mathrm{g} / \mathrm{L}$ was close to $1.8 \mu \mathrm{g} / \mathrm{L}$, i.e., the European maximum allowable concentration for inland surface waters (i.e., rivers and lakes and related artificial or heavily modified water bodies) as reported by Annex I, Part A: Environmental Quality Standards of DIRECTIVE 2013/39/EU [17]. The $0.2 \mu \mathrm{g} / \mathrm{L}$ concentration of DCMU corresponds to the annual average value for inland surface waters and other surface waters, and it is twice the maximum allowable concentration of a single pesticide in drinking water as regulated by the Drinking Water Directive $(0.1 \mu \mathrm{g} / \mathrm{L})$ [18]. With the purpose of investigating acute effects, two fluorescence-based bioassays were carried out: (i) steady-state chlorophyll $a$ (Chl-a) fluorescence emission spectra; (ii) kinetics measurements of the chlorophyll $a$ fluorescence transient. Chlorophyll $a$ fluorescence is an information-rich tool that can provide interesting insights about the interfering effects of chemical stressors on photosystem II (PSII) photochemistry and the photosynthetic process in general [19].

\section{Materials and Methods}

\subsection{Chlamydomonas reinhardtii Cell Suspensions}

Axenic cultures of green microalga Chlamydomonas reinhardtii (CC-125 wild type 137c, mating type +, purchased from Chlamydomonas Resource Center, University of Minnesota, USA) were grown in TAP growth medium (Gibco ${ }^{\circledR}$ TAP medium optimized for 
Chlamydomonas culture, purchased from Thermo Fisher Scientific, Waltham, MN, USA). C. reinhardtii liquid cultures (2:1 flask-to-medium ratio) was grown at $25 \pm 1{ }^{\circ} \mathrm{C}$ in autoclaved sterile Erlenmeyer Flasks stoppered with autoclaved sterile cotton wool buds. Erlenmeyer Flasks were kept in an orbital shaker incubator with thermostatic cupola (mod. 711/CT +, ASAL Srl, Milan) under constant agitation (150 rpm) and continuous illumination provided by a $16 \mathrm{~W}$ cool white fluorescent tube placed $20 \mathrm{~cm}$ above the culture flasks (Figure S1).

Cell counting was carried out using a counting chamber and a Reichert-Jung MicroStar 110 microscope, Leica Microsystems Wetzlar, Germany. Measurements of optical density at a fixed wavelength of $750 \mathrm{~nm}\left(\mathrm{OD}_{750 \mathrm{~nm}}\right)$ were performed in quartz cuvettes with $1 \mathrm{~cm}$ optical path lengths against TAP medium as reference (UV2 UV/Visible, Unicam Instruments, Cambridge, UK). Seven serial dilutions were prepared using a one-week growing C. reinhardtii cell culture (range of cells $/ \mathrm{mL}$ between $2 \times 10^{5}-1.2 \times 10^{6}$ cells $/ \mathrm{mL}$ ). At the wavelength of $750 \mathrm{~nm}$, the interferences due to light absorption by photosynthetic pigments are minimal [20]. The calibration curve was constructed by plotting $\mathrm{OD}_{750 \mathrm{~nm}} \mathrm{vs}$. $10^{5}$ cells $/ \mathrm{mL}$ values $(\mathrm{y}=0.0658 \times-0.0311)$ (Figure $\left.\mathrm{S} 2\right)$. Good agreement $\left(\mathrm{R}^{2}=0.9638\right)$ was found between $\mathrm{OD}_{750 \mathrm{~nm}}$ and $C$. reinhardtii cellular concentration.

\subsection{Herbicide DCMU Solutions}

A $2.5 \mathrm{~g} / \mathrm{L}$ stock solution of DCMU ( $\geq 98 \%$ purchased from Sigma-Aldrich, Milano, Italy) was prepared in methanol (assay GLC $\geq 99.9 \%$, obtained from Carlo Erba Srl, Italy), kept dark, and stored at $4{ }^{\circ} \mathrm{C}$ in a glass bottle. Before each photosynthesis-interference bioassay, dilutions with high-purity deionized water (Milli-Q system, Merck Millipore, Billerica, MA, USA) were carried out to obtain DCMU working solutions 10 times more concentrated than the final concentrations tested (i.e., $0.2,2$ and $20 \mu \mathrm{g} / \mathrm{L}$ ).

Before each bioassay, DCMU stock solution was verified through spectrophotometric measurements at $\lambda=250 \mathrm{~nm}$, which coincides with DCMU's absorbance peak in water [21]. The spectrophotometric measurements (Unicam UV2 UV/Visible spectrophotometer, Unicam Instruments Ltd, Arbury Road, Cambridge, United Kingdom) were carried out against high-purity deionized water in quartz cuvettes with $1 \mathrm{~cm}$ optical path lengths at $25^{\circ} \mathrm{C}$ on $1 / 200$ dilution of DCMU stock solutions ( $\lambda=250 \mathrm{~nm} ; 0.798 \pm 0.005$ absorbance units).

\subsection{Microalgae-Based Bioassays}

\subsubsection{Measurements of In Vivo Steady-State Chl-a Fluorescence}

Chlorophyll $a$ fluorescent analysis has become a widely used technique to measure photosynthetic efficiency. Emission at $684 \mathrm{~nm}\left(\mathrm{~F}_{684 \mathrm{~nm}}\right)$ is considered the main emission band associated with PSII at room temperature [22], mostly originating in PSII antenna complexes [23]. The increase in the $\mathrm{F}_{684} \mathrm{~nm}$ value reflects changes in photosystem II photochemistry associated with an inhibition of photosynthetic activity [24]. Each bioassay was performed in triplicate following the same experimental set-up (Figure 1):

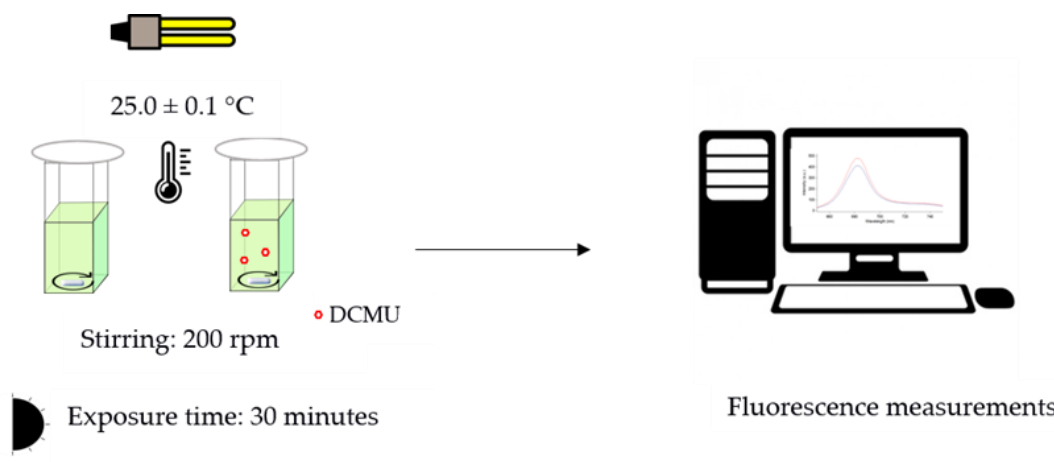

Figure 1. Schematic representation of experimental protocol used for the in vivo steady-state Chl-a fluorescence emission spectra. 
- Control microalgae cell suspensions: $2.70 \mathrm{~mL}$ of microalgae cell suspension $\left(\mathrm{OD}_{750 \mathrm{~nm}}\right.$ of $0.20 \pm 0.02)+0.30 \mathrm{~mL}$ of high-purity deionized water.

- DCMU-exposed microalgae cell suspensions: $2.70 \mathrm{~mL}$ of microalgae cell suspension $\left(\mathrm{OD}_{750 \mathrm{~nm}}\right.$ of $\left.0.20 \pm 0.02\right)+0.30 \mathrm{~mL}$ of DCMU working solutions (10 times more concentrated than the final concentrations tested, i.e., $0.2,2$, and $20 \mu \mathrm{g} / \mathrm{L}$ ).

All the microalgae cell suspensions were placed in quartz cuvettes with $1 \mathrm{~cm}$ optical path lengths at controlled temperature $\left(25.0 \pm 0.1{ }^{\circ} \mathrm{C}\right)$, under continuous light $(16 \mathrm{~W}$ cool white fluorescent tube placed $20 \mathrm{~cm}$ above), and under constant magnet stirring (200 rpm). During the exposure time, the cuvettes were covered with $20 \mathrm{~mm}$ diameter cellulose filter discs (Whatman ${ }^{\circledR}$ qualitative filter paper, Grade 1; Sigma Aldrich, Milan, Italy) to limit possible dust contamination of samples and water evaporation $(<5 \%)$, while ensuring a proper gaseous exchange between air and microalgae cell suspensions. After $30 \mathrm{~min}$, the fluorescence emission spectra were recorded at $25^{\circ} \mathrm{C}$ using a Cary Eclipse spectrofluorometer (Varian, USA) both on DCMU-exposed microalgae cell suspensions and on blank microalgae cell suspensions (Figure S3). Spectrofluorometer was set as follows: excitation wavelength $=489 \mathrm{~nm}$; range of emission wavelengths: 650 and $800 \mathrm{~nm}$; excitation and emission slits $10 \mathrm{~nm}$; scan rate $120 \mathrm{~nm} / \mathrm{min}$.

The comparison of $\mathrm{F}_{684 \mathrm{~nm}}$ values between exposed and control microalgae cell suspensions was used as an index to assess interference on photosystem II photochemistry, as previously described by Fai et al., 2007 [25], and calculated as follows:

$$
\% \iota=\left[\left(\mathrm{F}_{684 \mathrm{~nm} \mathrm{exp}} / \mathrm{F}_{684 \mathrm{~nm} \mathrm{blk}}\right)-1\right] \times 100
$$

where $\mathrm{F}_{684 \mathrm{~nm} \text { exp }}=$ mean of values of fluorescence emission at $684 \mathrm{~nm}$ (in arbitrary units) for DCMU-exposed microalgae cell suspensions, and $\mathrm{F}_{684 \mathrm{~nm} \text { blk }}=$ mean of values of fluorescence emission at $684 \mathrm{~nm}$ (in arbitrary units) for control microalgae cell suspensions.

\subsubsection{Kinetic Measurements of a Chl-a Fluorescence Transient}

The Kautsky effect is a known biophysical phenomenon of Chl-a fluorescence transient induction (or OJIP transient) observed when dark-adapted photosynthetic samples are exposed to saturating light intensities. The Kautsky effect includes two phases: a first exponential (less than a second) and a second one slowly decaying (few minutes). The first phase is called 'OJIP phase', where ' $\mathrm{O}$ ' stands for 'origin', i.e., the first measured minimal level, J and I are intermediate levels around 2 and $30 \mathrm{~ms}$, respectively, and P is the peak. Changes in fluorescence intensity during the OJIP phase have been mainly associated with changes in redox states of components of the linear photosynthetic electron transport chain of photosystem II, as well as to the kinetics of redox reactions that occur through it [26].

Thus, the OJIP phase can be potentially used for the characterization of PSII photochemistry, the electron transport activity, as well as to monitor the inhibition effects of photosynthesis stressors, including the herbicide DCMU [27]. OJIP tests were performed using a fluorometer developed under the 'Alert' program [28] as part of the 'Best' prototype [29]. This six-sample chambers fluorometer uses a non-modulated (continuous) LED light source for excitation $\left(\lambda_{\mathrm{ex}}=650 \mathrm{~nm}\right.$, intensity $127 \mu \mathrm{mol} \mathrm{m}{ }^{-2} \mathrm{~s}^{-1}$, duration $\left.11 \mathrm{~s}\right)$, $\lambda_{\mathrm{em}}=690-715 \mathrm{~nm}$. The spectra baseline was corrected with spectra of TAP growth medium.

Each bioassay was performed in triplicate following the same experimental setup (Figure 2). The microalgae cell suspensions were incubated for 20 min using same conditions described for in vivo steady-state fluorescence emission of Chl-a bioassays (Section 2.3.1, Figure 1). Then, microalgae cell suspensions were transferred into the sixsample chambers fluorometer and dark-adapted for $10 \mathrm{~min}$ before the fluorescence measurements. A scheme of the experimental protocol used in the kinetic measurements of Chl-a fluorescence transient is reported in Figure 2. 


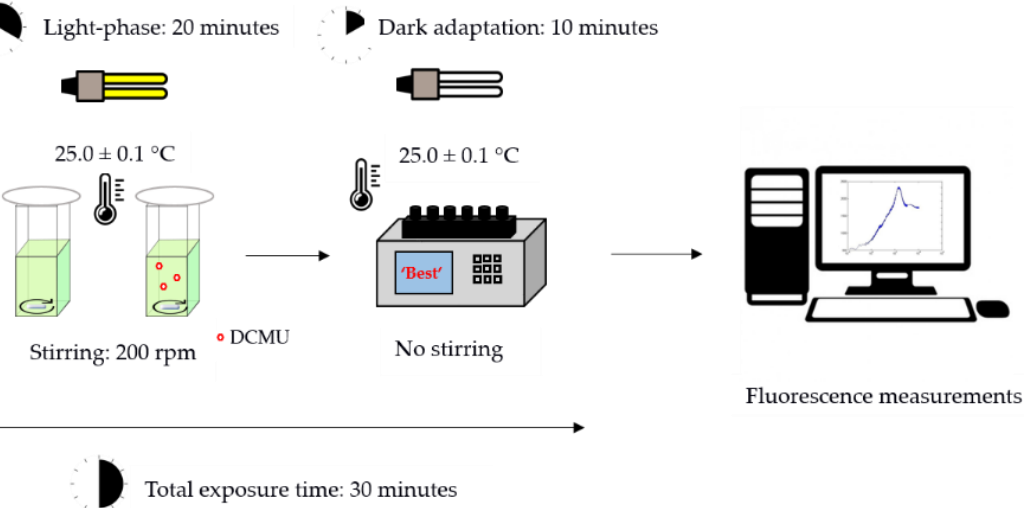

Figure 2. Schematic representation of experimental protocol used in the kinetic bioassays.

Analyses of Kautsky curves were performed using MatLab v7.8 (The MathWorks Inc., Natick, MA, USA). The following parameters of Kautsky curves were calculated:

- Fo (minimum of fluorescence intensity yield in the absence of photosynthetic light): calculated with data between 0.1 and $0.14 \mathrm{~ms}$ as the intercept of linear regression;

- $\mathrm{F}_{\mathrm{M}}$ (maximum of fluorescence intensity);

- $\quad \mathrm{F}_{8 \mathrm{~ms}}$ (fluorescence intensity at $8 \mathrm{~ms}$ ): average fluorescence values acquired at $8.0 \pm 0.1 \mathrm{~ms}$;

- $\mathrm{V}_{8 \mathrm{~ms}}$ (the relative variable fluorescence at $8 \mathrm{~ms}$ ) calculated as follows:

$$
\mathrm{V}_{8 \mathrm{~ms}}=\left(\mathrm{F}_{8 \mathrm{~ms}}-\mathrm{Fo}\right) /\left(\mathrm{F}_{\mathrm{M}}-\mathrm{Fo}\right)
$$

The comparison of $\mathrm{V}_{8} \mathrm{~ms}$ values between exposed and control microalgae cell suspensions was used as an index to assess interference on PSII photochemistry, and calculated as follows:

$$
\% \varepsilon=\left[\left(\mathrm{V}_{8 \mathrm{~ms} \exp }-\mathrm{V}_{8 \mathrm{~ms} \text { blk }}\right) /\left(1-\mathrm{V}_{8 \mathrm{~ms} \text { blk }}\right)\right] \times 100
$$

where $\mathrm{V}_{8 \mathrm{~ms} \text { blk }}=$ mean of $\mathrm{V}_{8 \mathrm{~ms}}$ values for control microalgae cell suspensions and $\mathrm{V}_{8 \mathrm{~ms}} \exp =$ mean of $\mathrm{V}_{8} \mathrm{~ms}$ values for DCMU-exposed microalgae cell suspensions.

\subsection{Data Analysis}

Each bioassay was performed in triplicate on the same day for all the three DCMU concentrations to assess the repeatability of the measurements. Reproducibility was verified by performing bioassays on three different days, starting from freshly prepared DCMU working solutions and C. reinhardtii cell suspensions. Statistical differences between exposed and control C. reinhardtii cell suspensions were analyzed using two-way analysis of variance (ANOVA) without replication testing for randomized block design. Randomized block design of ANOVA testing helped to reduce possible confounding factors that may affect the comparison between data acquired in different days of testing, e.g., possible differences between working C. reinhardtii cell suspensions prepared on different days [30].

\section{Results}

\subsection{In Vivo Steady-State Fluorescence Emission of Chl-a}

The results obtained for 30 min exposure to herbicide DCMU on the percentage increase in $\mathrm{F}_{684 \mathrm{~nm}}$ index (\% $\%$ ) are reported in Figure 3. 


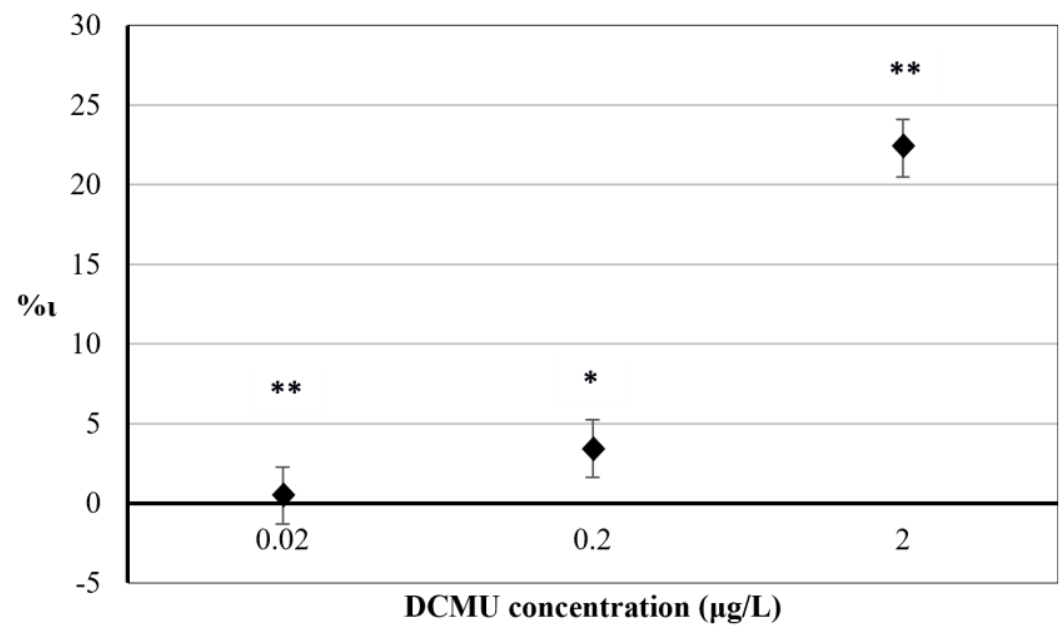

Figure 3. The comparison of $\mathrm{F}_{684} \mathrm{~nm}$ values between exposed and control microalgae cell suspensions after 30 min exposure to DCMU. RSD $\leq 15 \%$. Two-way ANOVA without replication testing was applied for statistical differences between means values of $\mathrm{F}_{684 \mathrm{~nm} \exp }$ and $\mathrm{F}_{684 \mathrm{~nm} \text { blk }}$. Statistical significance of the results is indicated with asterisks $\left({ }^{*} p<0.05 ;{ }^{* *} p<0.01\right)$.

A significant relationship between the mean variation of $\mathrm{F}_{684 \mathrm{~nm}}$ values in exposed and control C. reinhardtii cell suspensions was found at all concentrations tested $(p<0.05$ for $2 \mu \mathrm{g} / \mathrm{L}$ exposure and $p<0.01$ for 0.2 and $0.02 \mu \mathrm{g} / \mathrm{L}$, respectively). Positive values of $\% \mathrm{t}$ indicate interference in PSII photochemistry in exposed C. reinhardtii cell suspensions (compared to control cell suspensions) due to the inhibitory activity of DCMU on the photosynthetic electron transport chain. Results from exposure of $C$. reinhardtii cells to $2 \mu \mathrm{g} / \mathrm{L}$ DCMU showed a significant inhibition $(\% \iota=22.28)$. Exposures to $0.2 \mu \mathrm{g} / \mathrm{L}$ and $0.02 \mu \mathrm{g} / \mathrm{L}$ DCMU showed no significant differences between $\% \iota$ values $(\% \iota=3.48$ and $\% \iota=0.48$, respectively).

\subsection{Chlorophyll a Fluorescence Transient}

The Kautsky curves recorded after $30 \mathrm{~min}$ ( $20 \mathrm{~min}$ under light +10 of dark adaptation) exposure to the herbicide DCMU are reported in Figure 4.


a)



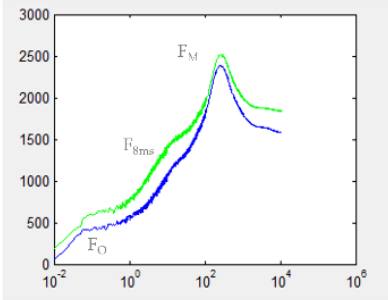

\begin{tabular}{l|l} 
time (ms) & time (ms)
\end{tabular}

Figure 4. OJIP phase of the Kautsky curves recorded for (a) $0.02 \mu \mathrm{g} / \mathrm{L}$ DCMU, (b) $0.2 \mu \mathrm{g} / \mathrm{L}$ DCMU, and (c) $2 \mu \mathrm{g} / \mathrm{L}$ DCMU-exposed microalgae cell suspensions (green line). Blank microalgae cell suspensions are in the blue line. Fo (minimal fluorescence, first reliable fluorescence value); $\mathrm{F}_{\mathrm{M}}$ (maximal fluorescence value at the peak of the OJIP curve under saturating illumination); $\mathrm{F}_{8 \mathrm{~ms}}$ (fluorescence value at 8 milliseconds). Baseline correction was performed using curves from TAP growth medium.

The percentage increase in $\mathrm{V}_{8 m s}(\% \varepsilon)$ is shown in Figure 5. 


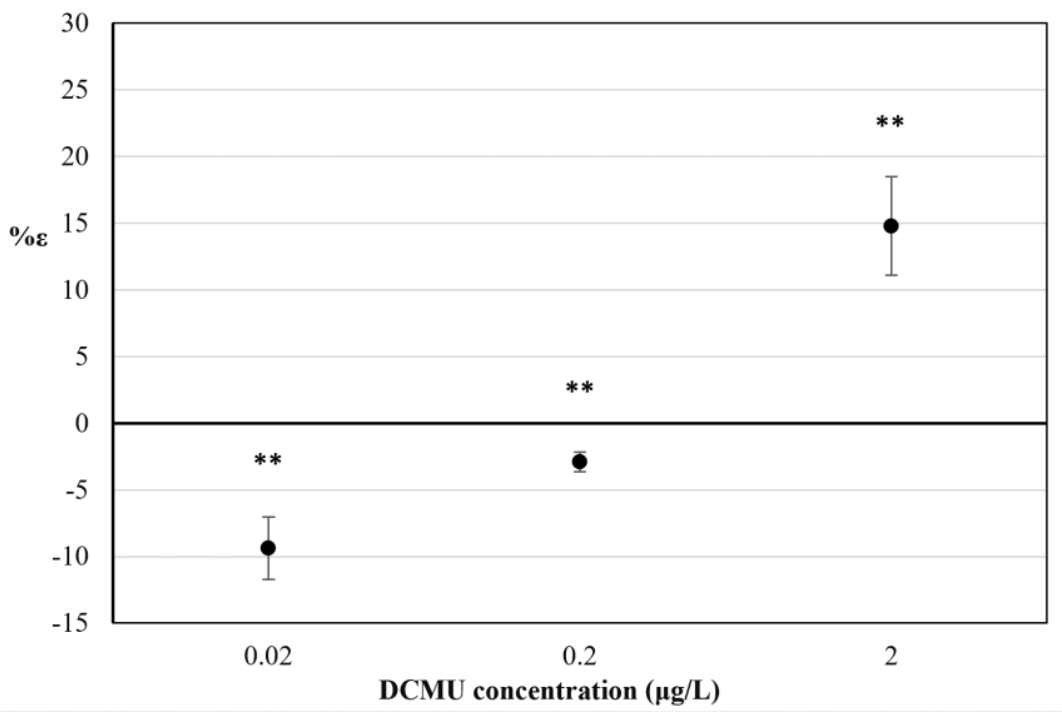

Figure 5. The percentage variation of $\mathrm{V}_{8 \mathrm{~ms}}$ index $(\% \varepsilon)$ after $30 \mathrm{~min}$ exposure to DCMU. $\mathrm{RSD} \leq 15 \%$. Two-way ANOVA without replication testing was applied for statistical differences between means values of $\mathrm{V}_{8 \mathrm{~ms}} \exp$ and $\mathrm{V}_{8} \mathrm{~ms}$ blk. Statistical significance of the results is indicated with asterisks $(* * p<0.01)$.

At all DCMU concentrations tested, a difference was found in the mean variation of $\mathrm{V}_{8 \mathrm{~ms}}$ values between exposed and control $C$. reinhardtii cell suspensions $(p<0.01)$. As for the results of in vivo steady-state fluorescence emission of Chl-a measurement (Section 3.2), a positive value of $\% \varepsilon$ for $2 \mu \mathrm{g} / \mathrm{L}$ DCMU exposure indicates interference in PSII photochemistry in exposed C. reinhardtii cell suspensions (compared to control cell suspensions), due to the inhibitory activity of DCMU on the photosynthetic electron transport chain. Negative values of \% $\%$ observed for 0.2 and $0.02 \mu \mathrm{g} / \mathrm{L}$ DCMU exposure correspond to a significant decrease in $\mathrm{V}_{8} \mathrm{~ms}$ for exposed C. reinhardtii cell suspensions (compared to control cell suspensions) and could be attributable to a presumably 'stimulatory-like' interference on PSII photochemistry. Decreases in $\mathrm{F}_{\mathrm{M}}$ values were observed for all $C$. reinhardtii cell suspensions exposed to sub- $\mu \mathrm{g} / \mathrm{L}(\leq 0.2 \mu \mathrm{g} / \mathrm{L})$ DCMU concentrations compared to control (Figure 4).

\section{Discussion}

Our results are consistent with the previous results obtained by Fai et al. (2007) for $3 \mu \mathrm{g} / \mathrm{L}$ DCMU exposures, using steady-state fluorescence emission spectra of Chl-a based bioassay [25]. Fai et al. (2007) worked with the green microalga Selenastrum capricornutum (also known as Raphidocelis subcapitata or Pseudokirchneriella subcapitata) that is used in the standard 72-hr growth inhibition assay for acute and chronic toxicity assessment [31]. Optimal response has been obtained after $30 \mathrm{~min}$ exposure of $S$. capricornutum cells to DCMU using a microplate-based protocol. The results of the percentage increase in $\mathrm{F}_{684 \mathrm{~nm}}$ $(\% \mathrm{l})$ have shown a positive linear association $\left(\mathrm{R}^{2}=0.8\right)$ with results from using the 72-h S. capricornutum growth inhibition assay [31]. Our method obtained results of a DCMU concentration 10-fold lower than those reported by Fai et al. (2007). With respect to the experimental protocol used by Fai et al. (2007) for S. capricornutum, it can be hypothesized that the exposure conditions of constant stirring and illumination adopted in our bioassays can promote the $C$. reinhardtii response to DCMU.

The fast kinetics of the Chl-a transient fluorescence and the polyphasic OJIP induction curve are thought to be largely determined by changes in the redox state of the primary PSII quinone $\left(Q_{A}\right)$, but also reflect interferences in the photosynthetic electron transport chain [32]. In particular, the parameters measured in our study $\mathrm{F}_{8 \mathrm{~ms}}$ and $\mathrm{V}_{8 \mathrm{~ms}}$ and its percentage increase $(\% \varepsilon)$ refer to the JI phase (approximately 3-30 ms) of the polyphasic 
OJIP induction curve, whose kinetics reflect the presence of (over)oxidized PQ molecules and the (partial) reduction in the PQ pool [33]. The positive value of the $\mathrm{V}_{8 \mathrm{~ms}}$ index observed for $2 \mu \mathrm{g} / \mathrm{L}$ DCMU exposures $(\% \varepsilon=14.77 \%)$ in Figure 5 can be associated with the inhibition of PSII of C. reinhardtii cells. It is widely known that DCMU inhibits PSII, thus blocking the plastoquinone pool (PQ-pool) reduction through the impairment of the electron transfer between primary and secondary PSII quinones, $\mathrm{Q}_{\mathrm{A}}$ and $\mathrm{Q}_{\mathrm{B}}$, respectively [34]. This impairment inhibits the so-called 'state 1' of the photosynthetic apparatus when the linear electron transfer (LET) from PSII to PSI occurs [35]. The LET is mostly active in the absence of DCMU, while in the presence of DCMU, the cyclic electron transport (CET) prevails over the LET, the so-called 'state 2' [36]. The decrease in fluorescence signals in C. reinhardtii cell cultures exposed to sub- $\mu$ g/L DCMU concentrations (Figure 4) and negative $\% \varepsilon$ values observed for $C$. reinhardtii cell suspensions exposed to the same DCMU concentrations (Figure 5) could be associated with a presumptive early mechanism of acclimation to DCMU-induced stress at sub- $\mu \mathrm{g} / \mathrm{L}$ doses. A decrease in excitation energy as fluorescence corresponds to a higher rate in energy utilization in photochemistry [37]. It could be hypothesized that partial inhibition of photosynthetic linear electron transport by DCMU at sub- $\mu \mathrm{g} / \mathrm{L}$ concentrations $(\leq 0.2 \mu \mathrm{g} / \mathrm{L})$ can affect the modulating energy flux through the state transitions, inducing a 'stimulatory-like' mechanism of the photosynthetic process downstream of PSII. Although it is widely accepted that variations in the polyphasic OJIP induction curve are mostly due to changes in the redox state of the reaction center complex of PSII, fast kinetics of the Chl-a fluorescence transient are also affected by changes occurring in the overall photosynthetic apparatus [26]. The imbalance between LET and CET, induced by partial inhibition of photosynthetic linear electron transport induced by exposure to sub- $\mu \mathrm{g} / \mathrm{L}$ DCMU concentrations $(\leq 0.2 \mu \mathrm{g} / \mathrm{L})$ and the parallel cyclic electron transport (CET) activity could influence PQ-pool redox poise and therefore induce the lowering fluorescence emission observed. The relationship between PQ-pool redox poise and LET/CET balance is widely accepted [32,36,38]. The PQ-pool redox poise can also influence state transitions [35] and modulate several redox-signaling pathways that can affect photosynthetic efficiency [39].

Therefore, the decrease in $\mathrm{F}_{\mathrm{M}}$ values (Figure 4) and negative $\% \varepsilon$ values observed for C. reinhardtii cell suspensions exposed to sub- $\mu$ g/L DCMU concentrations (Figure 5) could be attributed to the quenching of fluorescence due to an increased oxidation state of the plastoquinone (PQ) pool, as well as to a transition from LET to CET [40].

We can hypothesize the influence of these mechanisms on our results, but no data are available so far, and further measurements will be necessary to confirm this hypothesis. Moreover, other mechanisms could be involved. In C. reinhardtii wild type cells, the Calvin-Benson-Bassham cycle is partially active, although PSII was inhibited by DCMU, and it affects the number of electrons that can be allocated to CET [34]. The activity of recently identified stromal photosynthetic alternative electron transport pathways, such as flavodiiron proteins (FLV), seems to contribute to the Kautsky curve [41], as well as other modulators of in vivo Chl-a fluorescence, such as the thylakoidal transmembrane electrochemical potential $(\Delta \psi)$ [33]. Further studies will be necessary to support these hypotheses and characterize the subcellular mechanism(s) involved. Acute exposures to sub- $\mu \mathrm{g} / \mathrm{L}$ concentrations of DCMU can lead to other biomolecular effects. Significant modifications in the proteome of C. reinhardtii wild type strain CC-125 (mt+) have been observed after $6 \mathrm{~h}$ exposure to sub- $\mu \mathrm{g} / \mathrm{L}$ doses DCMU $\left(3.3 \times 10^{-9} \mathrm{M}\right.$, about $\left.0.8 \mu \mathrm{g} / \mathrm{L}\right)$ [42]. The observed proteome variation includes, among others, the upregulation of plastocyanin PCY1 (electron carrier that participates in electron transfer between P700 and the cytochrome b6-f complex in PSI) and the downregulation of LHCA4 (a binding protein part of the light-harvesting complex). Such modification in the C. reinhardtii proteome could lead to a functional remodeling of the photosynthetic machinery in exposed cultures.

Overall, future research is required to better investigate mechanisms responsible for the alteration observed in chlorophyll fluorescence parameters following sub- $\mu \mathrm{g} / \mathrm{L}$ DCMU 
exposures, as well as the possible effects on natural communities of green microalgae and/or on freshwater biofilms.

\section{Conclusions}

Chlorophyll $a$ fluorescence proved to be a valid short-term in vitro toxicological endpoint to highlight the interfering effects on the $C$. reinhardtii photosynthetic process. Both bioassays presented in this paper are potentially scalable and adaptable for high-throughput applications in ecotoxicity testing of environmental samples. If confirmed, the hypothesized acute 'stimulatory-like' effect on the photosynthetic process should carefully be considered for its implication in ecological risk assessment of real scenarios.

Supplementary Materials: The following are available online at https:/ / www.mdpi.com/article/ 10.3390/bios12020067/s1, Figure S1: Picture of C. reinhardii culture flasks. Details about culture conditions are provided in the main text; Figure S2: Calibration curve of $\mathrm{OD}_{750} \mathrm{~nm}$ vs. cell count. Each point represents a mean value of five replicate tests $(\% \mathrm{RSD}<5 \%)$; Figure S3: Example of a chlorophyll fluorescence spectra of $2 \mu \mathrm{g} / \mathrm{L}$ DCMU-exposed microalgae cell suspensions (red line) and of blank microalgae cell suspensions (blue line). Details about instrumental setup are provided in the main text.

Author Contributions: Conceptualization, G.G., R.D. and C.F.; methodology, G.G. and R.D.; formal analysis, G.C.; investigation, G.G. and G.C.; resources, R.D. and C.F.; data curation, G.C.; writingoriginal draft preparation, G.G.; writing—review and editing, G.G., D.Z., R.D. and C.F.; visualization, G.G. and D.Z.; supervision, R.D. and C.F.; project administration, R.D. and C.F.; funding acquisition, R.D. and C.F. All authors have read and agreed to the published version of the manuscript.

Funding: This research received no external funding.

Acknowledgments: This work has been partially supported by the ALERT program ('Integrated system of bio-sensors and sensors (BEST) for the monitoring of wholesomeness and quality, as well as for traceability in the cow milk chain') funded by the Italian Ministry for Economic Development under the Call Industria 2015 'New technologies for Made in Italy' (Grant MI 00195). This work has been also partially supported by the program 'E-crops-technologies for sustainable digital agriculture' funded by the National Operational Program Research and Innovation 2014-2020 under Axis II "Thematic Projects", Action "Clusters" in the "Agrifood" specialization area (Project code: ARS01_01136).

Conflicts of Interest: The authors declare no conflict of interest.

\section{References}

1. Green, P.G.; Young, T.M. Loading of the herbicide diuron into the California water system. Environ. Eng. Sci. 2006, $23,545-551$.

2. Peña, F.; Cárdenas, S.; Gallego, M.; Valcárcel, M. Analysis of phenylurea herbicides from plants by GC/MS. Talanta 2002, 56, 727-734.

3. Giacomazzi, S.; Cochet, N. Environmental impact of diuron transformation: A review. Chemosphere 2004, 56, $1021-1032$.

4. Da Rocha, M.S.; Arnold, L.L.; Pennington, K.L.; Muirhead, D.; Dodmane, P.R.; Anwar, M.M.; Cohen, S.M. Diuron-induced rat bladder epithelial cytotoxicity. Toxicol. Sci. 2012, 130, 281-288.

5. European Food Safety Authority. Reasoned opinion of EFSA: Review of the Existing Maximum Residue Levels (MRLs) for diuron according to article 12 of regulation (EC) No. 396/2005. EFSA J. 2011, 9, 2344. [CrossRef]

6. Agbaogun, B.K.; Fischer, K. Adsorption of phenylurea herbicides by tropical soils. Environ. Monit. Assess. 2020, $192,212$.

7. Liu, Y.; Xu, Z.; Wu, X.; Gui, W.; Zhu, G. Adsorption and desorption behavior of herbicide diuron on various Chinese cultivated soils. J. Hazard. Mater. 2010, 178, 462-468.

8. Marlatt, V.L.; Martyniuk, C.J. Biological responses to phenylurea herbicides in fish and amphibians: New directions for characterizing mechanisms of toxicity. Comp. Biochem. Physiol. C Toxicol. Pharm. 2017, 194, 9-21.

9. Kamarudin, N.A.; Zulkifli, S.Z.; Azmai, M.N.A.; Aziz, F.Z.A.; Ismail, A. Herbicide diuron as endocrine disrupting chemicals (EDCs) through histopathalogical analysis in gonads of Javanese medaka (Oryzias javanicus, Bleeker 1854). Animals 2020, 10, 525.

10. Moreira, L.B.; Diamante, G.; Giroux, M.; Coffin, S.; Xu, E.G.; Moledo de Souza Abessa, D.; Schlenk, D. Impacts of salinity and temperature on the thyroidogenic effects of the biocide diuron in Menidia beryllina. Environ. Sci. Technol. 2018, 52, $3146-3155$.

11. Moon, Y.S.; Kim, M.; Hong, C.P.; Kang, J.H.; Jung, J.H. Overlapping and unique toxic effects of three alternative antifouling biocides (Diuron, Irgarol $1051^{\circledR}$, Sea-Nine $211^{\circledR}$ ) on non-target marine fish. Ecotoxicol. Environ. Saf. 2019, 180, $23-32$. 
12. Nestler, H.; Groh, K.J.; Schönenberger, R.; Behra, R.; Schirmer, K.; Eggen, R.I.; Suter, M.J.F. Multiple-endpoint assay provides a detailed mechanistic view of responses to herbicide exposure in Chlamydomonas reinhardtii. Aquat. Toxicol. 2012, $214-224$.

13. Morin, S.; Chaumet, B.; Mazzella, N. A time-dose response model to assess diuron-induced photosynthesis inhibition in freshwater biofilms. Front. Environ. Sci. 2018, 6, 131.

14. Chaumet, B.; Morin, S.; Hourtané, O.; Artigas, J.; Delest, B.; Eon, M.; Mazzella, N. Flow conditions influence diuron toxicokinetics and toxicodynamics in freshwater biofilms. Sci. Total Environ. 2019, 652, 1242-1251.

15. Sasso, S.; Stibor, H.; Mittag, M.; Grossman, A.R. The Natural History of Model Organisms: From molecular manipulation of domesticated Chlamydomonas reinhardtii to survival in nature. Elife 2018, 7, e39233.

16. Cid, A.; Prado, R.; Rioboo, C.; Suarez-Bregua, P.; Herrero, C. Use of Microalgae as Biological Indicators of Pollution: Looking for New Relevant Cytotoxicity Endpoints; Johnsen, M.N., Ed.; Nova Science Publishers: New York, NY, USA, 2012; pp. 311-323.

17. Directive 2013/39/EU of the European Parliament and of the Council of 12 August 2013 amending Directives 2000/60/EC and 2008/105/EC as Regards Priority Substances in the Field of Water Policy. Available online: https://www.google.com/url?sa= t\&rct=j\&q=\&esrc=s\&source=web\&cd=\&ved=2ahUKEwidpb7-6cH1AhXOCd4KHdFZAjYQFnoECAUQAQ\&url=https \%3A \% 2F\%2Feur-lex.europa.eu\%2FLexUriServ\%2FLexUriServ.do\%3Furi\%3DOJ\%3AL\%3A2013\%3A226\%3A0001\%3A0017\%3Aen\% 3APDF\&usg=AOvVaw1YjeR01_YUxTs_BAKtm311 (accessed on 8 August 2021).

18. Council Directive 98/83/EC of 3 November 1998 on the Quality of Water Intended for Human Consumption. Available online: https:/ / eur-lex.europa.eu/legal-content/EN/TXT/?uri=celex\%3A31998L0083 (accessed on 8 August 2021).

19. Kalaji, H.M.; Schansker, G.; Ladle, R.J.; Goltsev, V.; Bosa, K.; Allakhverdiev, S.I.; Brestic, M.; Bussotti, F.; Calatayud, A.; Dabrowski, P.; et al. Frequently asked questions about in vivo chlorophyll fluorescence: Practical issues. Photosynth. Res. 2014, 122, 121-158.

20. Griffiths, M.J.; Garcin, C.; van Hille, R.P.; Harrison, S.T. Interference by pigment in the estimation of microalgal biomass concentration by optical density. J. Microbiol. Methods 2011, 85, 119-123.

21. Goswami, A.; Jiang, J.Q. Simultaneous quantification of gabapentin, sulfamethoxazole, terbutryn, terbuthylazine and diuron by uv-vis spectrophotometer. Biointerface Res. Appl. Chem. 2018, 8, 3111-3117.

22. Franck, F.; Juneau, P.; Popovic, R. Resolution of the photosystem I and photosystem II contributions to chlorophyll fluorescence of intact leaves at room temperature. Biochim. Biophys. Acta. (BBA)-Bioenerg 2002, 1556, 239-246.

23. Jee, G. Sixty-three years since Kautsky: Chlorophyll a fluorescence. Aust. J. Plant Physiol. 1995, 22, 131-160.

24. Eullaffroy, P.; Vernet, G. The F684/F735 chlorophyll fluorescence ratio: A potential tool for rapid detection and determination of herbicide phytotoxicity in algae. Water Res. 2003, 37, 1983-1990.

25. Fai, P.B.; Grant, A.; Reid, B. Chlorophyll a fluorescence as a biomarker for rapid toxicity assessment. Environ. Toxicol. Chem. 2007, $26,1520-1531$.

26. Stirbet, A. On the relation between the Kautsky effect (chlorophyll a fluorescence induction) and Photosystem II: Basics and applications of the OJIP fluorescence transient. J. Photochem. Photobiol. B 2011, 104, 236-257.

27. Stirbet, A.; Riznichenko, G.Y.; Rubin, A.B. Modeling chlorophyll a fluorescence transient: Relation to photosynthesis. Biochemistry 2014, 79, 291-323.

28. Lombardo, A.; Boselli, C.; Amatiste, S.; Ninci, S.; Frazzoli, C.; Dragone, R.; De Rossi, A.; Grasso, G.; Mantovani, A.; Brajon, G From invention to innovation: Risk analysis to integrate one health technology in the dairy farm. Front. Public Health 2017, 5, 302.

29. System (Best-Integrated Toxicity (Bio) Sensor's System for Hazard Analysis and Management in the Food Chain and the Environment) for Environment Diagnostic and Monitoring and Self-Control of Food Chain, Including Primary Production, and Relevant Method for Quick Management of Hazard. Available online: https://patents.google.com/patent/EP2304428B1/en?oq= EP2304428B1 (accessed on 8 August 2021).

30. Dragone, R.; Grasso, G.; Frazzoli, C. Amperometric Cytosensor for Studying Mitochondrial Interferences Induced by Plasticizers Bisphenol B and Bisphenol A. Molecules 2020, 25, 5185.

31. ISO 8692:1989; Water Quality-Fresh Water Algal Growth Inhibition Test with Scenedesmus Subspicatus and Selenastrum Capricornutum. International Organisation for Standardisation: Geneva, Switzerland, 1989; 1-6.

32. Tóth, S.Z.; Schansker, G.; Strasser, R.J. A non-invasive assay of the plastoquinone pool redox state based on the OJIP-transient. Photosynth. Res. 2007, 93, 193-203.

33. Samson, G.; Prášil, O.; Yaakoubd, B. Photochemical and thermal phases of chlorophyll a fluorescence. Photosynthetica 1999, 37, 163-182.

34. Alric, J.; Lavergne, J.; Rappaport, F. Redox and ATP control of photosynthetic cyclic electron flow in Chlamydomonas reinhardtii (I) aerobic conditions. Biochim. Biophys Acta. (BBA)-Bioenerg. 2010, 1797, 44-51.

35. Finazzi, G.; Furia, A.; Barbagallo, R.P.; Forti, G. State transitions, cyclic and linear electron transport and photophosphorylation in Chlamydomonas reinhardtii. Biochim. Biophys Acta. (BBA)-Bioenerg. 1999, 1413, 117-129.

36. Alric, J. The plastoquinone pool, poised for cyclic electron flow? Front. Plant Sci. 2015, 6, 540.

37. Zhu, X.G.; Baker, N.R.; Desturler, E.; Ort, D.R.; Long, S.P. Chlorophyll a fluorescence induction kinetics in leaves predicted from a model describing each discrete step of excitation energy and electron transfer associated with photosystem II. Planta 2015, 223, 114-133.

38. Nawrocki, W.J.; Bailleul, B.; Cardol, P.; Rappaport, F.; Wollman, F.A.; Joliot, P. Maximal cyclic electron flow rate is independent of PGRL1 in Chlamydomonas. Biochim. Biophys Acta (BBA)-Bioenerg 2019, 1860, 425-432. 
39. Foyer, C.H.; Neukermans, J.; Queval, G.; Noctor, G.; Harbinson, J. Photosynthetic control of electron transport and the regulation of gene expression. J. Exp. Bot. 2012, 63, 1637-1661.

40. Finazzi, G.; Rappaport, F.; Furia, A.; Fleischmann, M.; Rochaix, J.D.; Zito, F.; Forti, G. Involvement of state transitions in the switch between linear and cyclic electron flow in Chlamydomonas reinhardtii. EMBO Rep. 2002, 3, $280-285$.

41. Alric, J.; Johnson, X. Alternative electron transport pathways in photosynthesis: A confluence of regulation. Curr. Opin. Plant Biol. 2017, 37, 78-86.

42. Nestler, H.; Groh, K.J.; Schönenberger, R.; Eggen, R.I.; Suter, M.J.F. Linking proteome responses with physiological and biochemical effects in herbicide-exposed Chlamydomonas reinhardtii. J. Proteom. 2012, 75, 5370-5385. 